\title{
ANALISIS PENGGUNAAN RENOVATION TOOLS BIM DALAM PROYEK RENOVASI KONSTRUKSI DI KABUPATEN KAMPAR
}

\author{
Muhd. Arief Al Husaini', Indra Kuswoyo' \\ Jurusan Arsitektur, Fakultas Teknik, Universitas Riau \\ E-mail: muhd.arief@lecturer.unri.ac.id, indra.kuswoyo@lecturer.unri.ac.id
}

\author{
Informasi Naskah: \\ Diterima: \\ 16 April 2021 \\ Diterbitkan: \\ 3 Juni 2021
}

\begin{abstract}
The act of regional autonomy provides rights to the regions to set a wheel government administration in the regions. However, the central government provides rules and recommendations such as laws and government regulations. Kampar is one of the districts in Riau Province that focus on infrastructure development. Kampar district set up infrastructure development through collaboration between the official work unit (SKPD) and partners such as consultant and contractor. The newest references such as architect law no 6 in 2017 and ordinance ministry of PUPR no 22 in 2018 that construction field must be managing a professional person and using Building Information Modelling (BIM) method. One of the projects is building and sector renovation. This research aim is to know renovation tools BIM using as a method in a renovation projects. This research is using qualitative research method with deeply interview and questionnaire to official work unit (SKPD) and partners such as consultant and contractor. The result of this research is getting that almost of all SKPD doing renovation project but is not using renovation tool BIM method. Besides, stakeholders are lacking of understand the meaning of the ordinance ministry of PUPR no 22 in 2018 . The recommendation of this study is the transfer of technology to the renovation tools method in carrying out renovation projects.
\end{abstract}

Keyword: Construction, Renovation Tools, Building Information Modelling

Abstrak: Undang-undang otonomi daerah memberikan hak kepada daerah untuk mengatur roda pemerintahan di daerah. Namun, pemerintah pusat memberikan aturan dan rekomendasi seperti undang-undang dan peraturan pemerintah. Pemerintah daerah Kabupaten Kampar salah satu kabupaten di Provinsi Riau yang fokus melakukan pembangunan infrastruktur. Pemerintah menyiapkan pembangunan melalui kerja sama organisasi perangkat daerah melalui satuan kerja perangkat dinas (SKPD) dengan rekanan seperti konsultan dan kontraktor. Rujukan terbaru seperti Undang-undang Arsitek no 6 tahun 2017 dan peraturan menteri PUPR no 22 tahun 2018 bahwa bidang konstruksi dikelola oleh profesional dan menggunakan metode Building Information Modelling (BIM). Salah satu proyek adalah renovasi bangunan dan kawasan. Penelitian ini bertujuan untuk mengetahui penggunaan renovation tools BIM sebagai metode dalam proyek renovasi. Metode yang digunakan adalah metode kualitatif dengan melakukan wawancara dan kuisioner kepada SKPD dan rekanan (konsultan dan kontraktor). Hasil penelitian ini didapatkan hampir semua SKPD melakukan proyek renovasi namun tidak menggunakan metode renovation tools BIM. Selain itu, stakeholder kurang memahami maksud peraturan menteri no 22 tahun 2018. Rekomendasi penelitian ini adalah peralihan teknologi menuju metode renovation tools dalam melakukan proyek renovasi.

Kata Kunci: Konstruksi, Renovation Tools, Building Information Modelling 


\section{PENDAHULUAN}

Undang-Undang Arsitek nomor 6 tahun 2020 dalam pasal 4 mengatakan bahwa layanan praktik arsitek adalah penyusunan studi awal, perencanaan, pelestarian, penyusunan dokumen teknis dan pengawasan pelaksanaan konstruksi bangunan. Pelayanan tersebut harus dilakukan dengan asas profesional, integritas, keamanan dan keselamatan, dan berkelanjutan. Sehinga dapat diartikan bahwa praktek konstruksi harus melibatkan tenaga ahli dan cara kerja (metode) yang efektif.

Menurut Peraturan Menteri PUPR nomor 22 tahun 2018 dalam ketentuan umum diungkapkan pengelolaan teknis bangunan gedung negara adalah pemberian bantuan teknis oleh Menteri kepada K/L atau Organisasi Perangkat Daerah (OPD) dalam pembangunan bangunan gedung negara. Selanjutnya dikatakan penyelenggara pembangunan adalah pengguna anggaran dan penyedia jasa konstruksi. Hal ini menunjukkan adanya kerjasama pemerintah daerah dan penyedia jasa konstruksi seperti profesi arsitek dan profesi lainnya.

Dalam hal ini, OPD memiliki peran penting dalam penyelenggaraan konstruksi di daerah yang dibagi dalam perangkat kerja terkait seperti Satuan Perangkat Kerja Dinas (SKPD). Otonomi daerah yang berlaku memberikan keleluasaan yang berdasar kepada daerah dalam melaksanakan proyek konstruksi. Dalam lampiran peraturan yang sama diwajibkan penggunaan building information modelling (BIM) pada proyek bangunan negara tidak sederhana. Namun, kedepannya diarahkan semua proyek perencanaan dilakukan dengan metode building information modelling (BIM) agar tercapai efisiensi dan informasi perencanaan yang akurat.

Berdasarkan isu diatas seharusnya pemerintah daerah Kabupaten Kampar melalui SKPD penyelenggara kegiataan konstruksi sebaiknya memahami amanat Undang-Undang Arsitek no 6 tahun 2020 dan Permen PUPR no 22 tahun 2018 dengan memberikan persyaratan setiap proyek perencanaan menggunakan metode building information modelling (BIM). Salah satu upaya tentu dengan menyediakan tenaga ahli di satuan dinas dan rekanan kerja yang memahami building information modelling (BIM).

Pemerintah Kabuapten Kampar dalam hal ini selaku penyelenggara daerah membentuk SKPD dengan fungsi kegiatan konstruksi seperti Dinas Pekerjaan Umum dan Penataan Ruang (PUPR), Dinas Perumahan dan Permukiman (Perkim), Dinas Lingkungan Hidup (DLH), serta dinas lain yang dapat melaksanakan proyek konstruksi sesuai kebutuhan internal masing-masing. Sehingga dapat disimpulkan hampir semua SKPD dimungkinkan melaksanakan proyek konstruksi.

Perhatian utama dalam penelitian ini adalah melihat apakah SKPD mengedepankan penggunaan metode renovation tools building information modelling (BIM) dalam pelaksanaan proyek renovasi bangunan maupun kawasan di wilayah kerja Kabupaten Kampar. Metode renovation tools ini akan memberikan kemudahan dalam proses perencanaan, pengawasan, dan proses pelaksanaan. Setiap aspek dalam gambar memiliki arti dan status yang berbeda seperti objek eksisting, objek penambahan baru, dan objek yang harus dihilangkan. Masing-masing status akan menghindarkan kesalahan informasi dalam tindakan, sehingga setiap tahapan akan efektif dan mudah dilaksanakan.

Manfaat penelitian ini tentunya untuk mengukur pemahaman dasar terhadap undang-undang arsitek dan Permen PUPR no 22 tahun 2018 dalam melaksanakan proyek renovasi konstruksi melalui metode renovation tools yang efektif dan efisien. Sehingga dapat memberikan saran kepada pemerintah daerah dalam menggambil kebijakan dan pemilihan rekanan dalam proses konstruksi.

\section{TINJAUAN PUSTAKA}

Permen PU no 24 tahun 2008 mengatakan pemeliharaan bangunan 
gedung adalah kegiatan menjaga keandalan bangunan gedung beserta sarana dan prasarananya agar bangunan gedung selalu layak digunakan. Ada beberapa metode penilaian kondisi bangunan gedung yang lebih sistematis dan memungkinkan adanya keseragaman atau standarisasi yang telah dikembangkan oleh para ahli, salah satunya adalah risk management, pengamatan penurunan kondisi dan indeks kondisi (Susan, dkk, 2016).

Proses konstruksi membutuhkan teknologi, metode, konsep dan inovasi dalam mencapai tujuan pelaksanaan konstruksi seperti kualitas desain dan fisik akhir (Rahmawati, 2014). Building information modelling (BIM) memiliki kemampuan untuk memfasilitasi koordinasi multidisiplin, integrasi desain 3d, analisis, estimasi biaya, dan penjadwalan konstruksi (McArthur, 2015). Perusahaan konsultan dan kontraktor di DKI Jakarta telah banyak menggunakan building information modelling (BIM) dalam proses komunikasi tahapan konstruksi dan mendapatkan banyak manfaat (Raflis, dkk, 2018).

Setiap tahap dalam renovasi, file filter Renovation Tools di Archicad adalah alat yang ampuh untuk mengatur apa yang lama dan apa yang baru dalam proyek renovasi, sehingga mengetahui apa yang ada, apa yang harus dihancurkan, dan yang baru dalam renovasi (Fontan, 2016). Selanjutnya dikatakan bahwa terdapat filter renovasi berbeda yang dibuat di archicad secara default yang menyaring informasi yaitu :

- Rencana yang ada

- Rencana pembongkaran

- Setelah pembongkaran

- Konstruksi baru

- Status yang direncanakan

\section{METODOLOGI PENELITIAN}

Penelitian ini menggunakan metode kualitatif aplikasi atau terapan (applied research) yang bertujuan untuk memberikan pencerahan atas suatu gejala yang menjadi sorotan (Raco, 2010). Sasaran yang ingin dicapai membantu objek penelitian untuk menelusur solusi terhadap masalah yang disorot. Tahapan penelitian adalah identifikasi masalah, penelusuran kepustakaan, maksd dan tujuan penelitian, pengumpulan data, analisa dan penafsiran data, dan pelaporan (Creswell, 2014). Teknik pengumpulan data melalui wawancara dan kuisioner kepada SKPD Dinas yang berkaitan dengan konstruksi dan Konsultan / kontraktor di Kabupaten Kampar.

\section{HASIL PENELITIAN DAN PEMBAHASAN}

SKPD yang menangani bidang konstruksi didominasi oleh SKPD Dinas Pekerjaan Umum dan Penataan Ruang (PUPR) dan SKPD Dinas Perumahan dan Permukiman (Perkim). Namun SKPD lainnya dimungkinkan untuk melaksanakan proyek, baik dengan kerjasama rekanan maupun meminjam tenaga ahli ke Dinas PUPR dan Perkim. Beberapa contoh pekerjaan renovasi seperti perencanaan rehab mushalla komplek perkantoran bupati lama, rehab SDN 012 Batu Langka Kecil Kecamatan Kuok, rehab kantor labkesda, rehab hatchery indoor patin, rehabilitasi kampung tradisional Pulau Belimbing Kuok dan lain sebagainya (sumber : Sistem Informasi Rencana Umum Pengadaan berbasis Web, 2021).

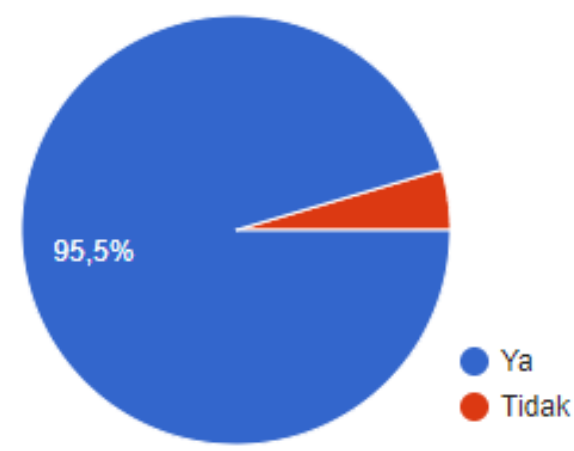

Gambar 1. Presentase SKPD melaksanakan proyek rehabilitasi konstruksi

Salah satu rujukan terbaru dalam pelaksanaan konstruksi adalah Peraturan Menteri PUPR no 22 tahun 2018 yang mengatur tentang pembangunan bangunan gedung negara serta Undangundang Arsitek no 6 tahun 2017. Kedua aturan tersebut mengatur pihak yang berperan dalam penyelenggaran konstruksi di Indonesia hingga ke daerah. 
Stakeholder yang berkaitan dengan proyek konstruksi sebaiknya memahami rujukan tersebut. Berdasarkan data survey bahwa stakholder baik SKPD maupun rekanan (konsultan dan kontraktor) di Kabupaten Kampar sebanyak 68,2\% tidak memahami secara spesifik terhadap kedua rujukan terbaru tersebut.

Dalam Permen PUPR no 22 tahun 2018 jelas mengatakan mengenai persyaratan adminsistratif, klasifikasi, berbagai standar, pembiayaan, perencanaan, perawaran, pihak terkait, dan teknis dalam konstruksi bangunan. Serta dalam lampirannya mewajibkan dan merekomendasikan penggunaan building information modelling (BIM). Sedangkan dalam Undang-undang Arsitek no 6 tahun 2017 secara jelas mengatakan asas dan tujuan, pelayanan praktik arsitek, persyaratan, lisensi, keprofesian dalam konstruksi. Sehingga dari kedua aturan dapat menjadi dasar pelaksana konstruksi secara efektif dan efisien yang dilakukan oleh pihak profesional dan memiliki kompetensi dalam industri konstruksi.

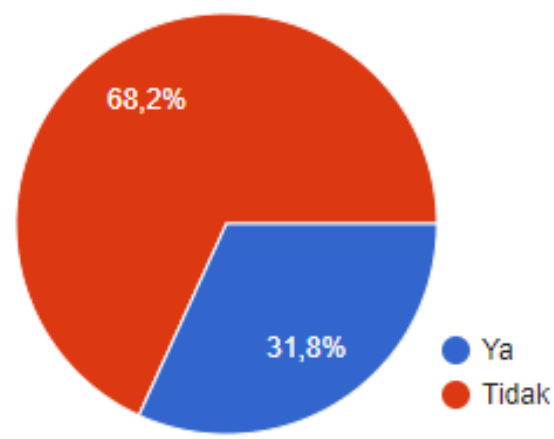

Gambar 2. Presentase SKPD dan rekanan dalam memahami Permen PUPR no 22 tahun 2018 dan UU Arsitek no 6 tahun 2017

Berdasarkan data yang diperoleh serta sejalan dengan pemahaman dengan rujukan aturan di atas didapatkan $90,9 \%$ stakeholder tidak menggunakan metode building information modelling (BIM) dalam proses konstruksi baik perencanaan, pengawasan, maupun pelaksanaan dalam konstruksi. Stakeholder SKPD dan rekanan masih masih menggunakan metode konvensional dalam proses konstruksi dengan penggunaan software Autocad dan Sketcup.

Menurut Husaini (2018) metode konvensional memiliki kelemahan dalam pelaksanaan seperti rendahnya tingkat efisien, waktu pembuatan dokumen yang lama, tingginya biaya, akurasi dan ketelitian yang rendah, dan kuranya transparansi. Untuk itu, kedepannya melalui peraturan diatas direkomendasikan penggunaan metode building information modelling (BIM). Banyaknya proyek renovasi di lingkungan Pemerintah Kabupaten Kampar perlu terobosan sebuah meto de konstruksi yang efektif dan akurat sehingga setiap elemen dalam renovasi dapat diberikan status.

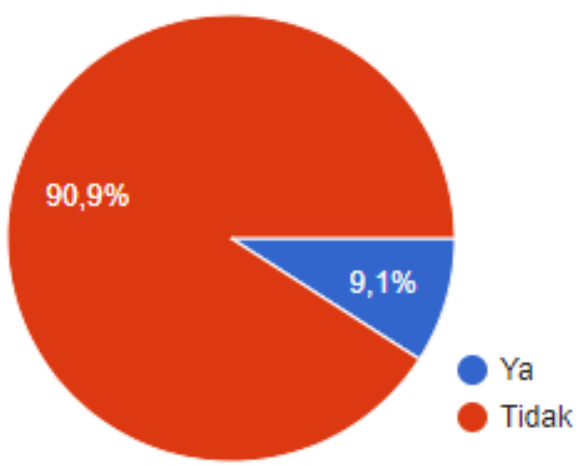

Gambar 3. Presentase stakeholder menggunakan building information modelling (BIM)

Berdasarkan data yang diperoleh bahwa 95\% stakeholder konstruksi di lingkungan Pemerintah Kabupaten Kampar tidak menerapkan metode renovation tools BIM dalam melaksanakan proyek renovasi baik skala bangunan maupun skala kawasan. Berbeda halnya dengan perencanaan gedung baru yang lebih mudah karena setiap elemen arsitektur dalam gambar berstatus elemen baru. Sedangkan dalam proyek renovasi merupakan proyek yang perlu penanganan dan metode kerja yang spesifik sebab setiap elemen arsitektur memiliki status yang berbeda. Status elemen arsitektur tersebut seperti elemen eksisting, elemen yang dihilangkan, elemen setelah dihilangkan, dan elemen baru. 


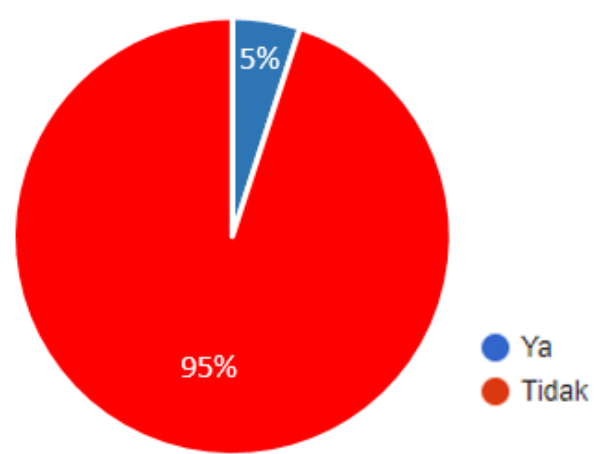

Gambar 4. Presentase SKPD dan rekanan menerapkan renovation tool BIM dalam renovasi

Setiap elemen tersebut perlu diberikan status dalam dokumen teknis renovasi arsitektur agar tidak terjadi salah informasi yang menyebabkan terjadinya kesalahan dalam pelaksanaan renovasi konstruksi. Oleh karena itu, memerlukan sebuah aplikasi yang mewadahi status elemen tersebut dalam renovasi. Salah satu metode perancangan yang mewadahi tindakan renovasi tersebut adalah renovation tools BIM pada sofware Archicad 24.

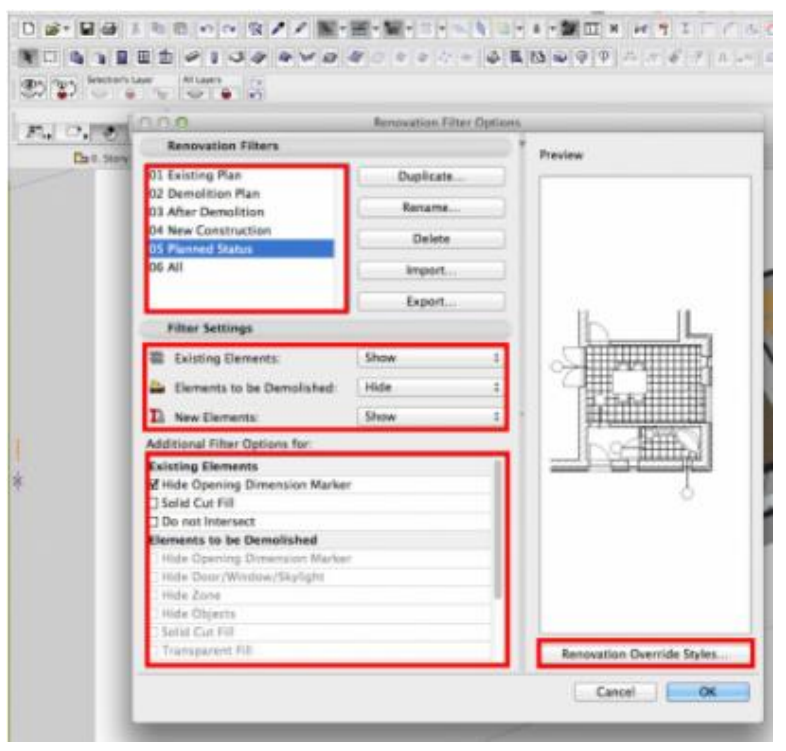

Gambar 5. Tampilan renovation tools untuk tindakan renovasi pada archicad 24

\section{KESIMPULAN}

Saat ini hampir semua proyek renovasi konstruksi didominasi oleh SKPD PUPR dan SKPD Perkim karena memiliki tenaga ahli khusus dibidang konstruksi, namun SKPD lainnya tetap diberikan wewenang melakukan tindakan renovasi dengan meminjam tenaga ahli pada SKPD sebelumnya. SKPD dan rekanan tidak memahami secara spesifik Permen PUPR no 22 tahun 2018 dan UU Arsitek no 6 tahun 2017. SKPD dan rekanan konstruksi tidak menggunakan metode renovation tools BIM dalam proyek renovasi/ rehabilitasi sehingga metode yang dugunakan adalah metode konvensional.

Saran yang diberikan kepada SKPD pemerintah daerah Kabupaten Kampar selaku penyelenggara konstruksi yang diamanatkan Permen PUPR no 22 tahun 2018 sebaiknya memahami secara spesifik tentang metode terbaru dan kedepannya memasukkan metode tersebut dalam proses konstruksi termasuk renovasi. Rekanan (konsultan dan konstraktor) saatnya melakukan alih teknologi dari metode konvensional menuju metode terbaru yaitu building information modelling (BIM) dalam proses konstruksi sehingga hasil pekerjaan akan lebih efisien dan akurat. Kedepannya SKPD dapat membentuk kelompok pengkaji penerapan building information modelling (BIM) dilingkungan konstruksi pemerintah daerah Kabupaten Kampar.

\section{UCAPAN TERIMA KASIH}

Penulis mengucapkan terimakasih kepada LPPM Universitas Riau telah memberikan dukungan pendanaan pelaksanaan penelitian melalui hibah penelitian DIPA Universitas Riau nomor kontrak 590/UN.19.5.1.3/PT.01.03/2021 sehingga kegiatan penelitian dapat terlaksana dengan baik.

\section{DAFTAR PUSTAKA}

Creswell, j. W. (2014). Research Design: Qualitative, Quantitative and Mixed Methods Approaches, 4 Edition. London: Sage.

Fontan, Eugenio. (2016). Renovation and Rehabilitation Projects Introduction to Renovation Filters. Dikutip di weareenzyme tanggal 05 April 2021.

Husaini, M. Arief. (2018). Analisa Pemahaman Mahasiswa Arsitektur Tentang Metode Building Information Modelling (BIM) Untuk Mendukung Revolusi Industri 4.0 Bidang Kontruksi Di Provinsi Riau. 
Prosiding. Seminar Nasional Teknoprenuer UPP "Peran Perguruan Tinggi Meningkatkan Kompetensi Lokal Menghadapi Revolusi Industri 4.0. Pasir Pengaraian. Riau.

McArthur, J. J., 2015) A Building Information Management (BIM) Framework and Supporting Case Study for Existing Building Operations, Maintenance and Sustainability. Procedia Engineering, 118, pp. 1104-1111.

Peraturan Menteri Pekerjaan Umum dan Penataan Ruang Republik Indoensia Nomor 22 Tahun 2018

Raco, J. R. (2010). Metode Penelitian Kualitatif : Jenis, Karakteristik, dan Keunggulannya. Jakarta : Grasindo.

Raflis., Yuwono, E. Y., Rayshanda. (2018). Manfaat Penggunaan Building Information Modelling (BIM) Pada Proyek Konstruksi Sebagai Media Komunikasi Stakeholders. Jurnal Construction Engineering and Sustainable Development Vol 01 no 02.

Rahmawati, Y., N. Anwar., \&C. Utomo. (2013). A Concept of Successful Collaborative Design towards Sustainability of Project Development. International Journal of Social, Human Science and Engineering, 7, 219-225

Undang-undang Arsitek Republik Indonesia Nomor 6 Thaun 2017.

Watty, S., Pratiwi, R., Syahrudin. (2016). Studi Penentuan Indeks Kondisi Bangunan Dan Biaya Renovasi Bangunan Lama Fakultas Kehutanan Universitas Tanjungpura Pontianak. Jurnal JeLAST vol 3 no 3. 